\title{
مذبحة التراث في الثقافة العربية المعاصرة
}

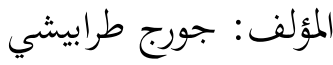 \\ الناشر: دار الساقي، لندن، 1993م --(135صفحة)
}

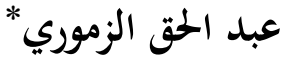

ما فتئ جورج طرابيشي منذ بضع سنوات يتتبع أصحاب المشاريع الفكرية العربية المعاصرة بالتحليل والنقد وإرجاع دعاويهم إلى أصولما والتنبيه إلى غثّها وسمينها (دراسته الضافية لمشروع حسن حنفي من العقيدة للثورة، وكذلك لمشروع الجابري في إعادة بناء العقل العربي...). وها هو ذا يتوقف من جديد عند مواقف بعض المثقفين العرب المعاصرين من إشكالية لا تزال تثنير حولها سيولاً من الحبر: المعاصرّة والإرث التراثي، في كتاب جاء أكثر "استفزازًا" وسجالية، بعنوان مذبحة التراث في الثقافة العربية المعاصرة، صدر عن دار الساقي بلندن سنة 1993، ويحتوي 135 صفحة من الحجم المتوسط.

وقد قسمه ثلاثة أقسام -أو "مذابح نظرية"- تغرّض في أولها للتيار الماركسي، وفي الثاني للتيار القومي، وفي الثالث لما أسماه بالتيار التعلمي، مصدِّراً عرضه بمقدمة قصيرة علل فيها حديثه عن المذبحة التي يقوم هها عينة من المثقفين موضوع الدراسة للتراث. وهي مذبحة لأفا تكشف منذ هزيمة 1967 "عن مأزق برتي

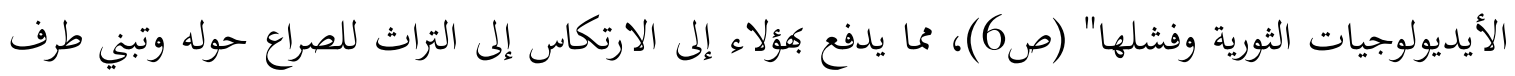
فيه ضد آخر، أو لتحويله إلى فكرانيّة (أيديولوجيا) تراثية خالصة.

وهذه العودة إلى التراث عند العرب محكومة، كما يرى المؤلف، "بجرح نرجسي ذي طبيعة أنثروبولوجية"؛ وهذه العقدة قاسم مشترك يجمعهم ببقية الشعوب غير الغربية. ولكن هذا الجرح يزداد اتساعاً

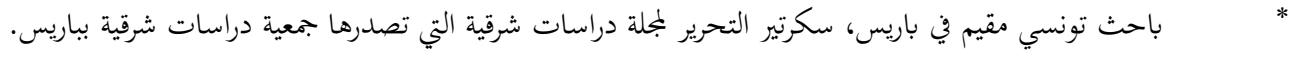


ونزيفاً بحكم الهزيمة العربية أمام المشروع الصهيوني (ص6). ويرى المؤلف أن التراث "المؤدج" هو في جميع الحالات فاقد للحقيقة التاريخية مهما اختلف الموقع الذي نتعامل منه معه، ومهما اختلفت الأساليب والمناهج المعتمدة في ذلك التعامل. وعلى ذلك يهدد طرابيشي طبيعة اللحظة التي نعيشها بوصفها "لحظة

$$
\text { أيديولوجية" بامتياز (ص7). }
$$

وتكمن قوة هذا التحديد وقيمته في إطلاقيته وجعله المدار المحرك لكل التحليلات التالية، فهو عند

المؤلف حقيقة ثابتة لا تحتمل المساءلة أو المراجعة، وهو البداهة ذاتا، ويتوقف على التسليم بها قبول منتجاتما اللاحقة. وانطلاقاً من هذه القاعدة المؤسسة، يمضي جورج طرابيشي في عرضه وتحليله لمظاهر هذه "المذبحة" عندن بمثلين اختارهم عن التيار الماركسي (توفيق سلوم)، والتيار القومي بنموذجيه: العلماني (زكي الأرسوزي)، والإسلامي (محمد عمارة)، والتيار العلمي بفرعيه: البراغماتي (زكي نجيب محمود) والمعريف

$$
\text { (الإبستمولوجي) (محمد عابد الجابري). }
$$

أن أول ما يلفت نظر القارئ لهذا الكتاب الاختلال الكبير بين أقسامه. ففي حين خصص "للمذبحة" التي قام بها مثثل التيار الماركسي ست صفحات ونصفاً، تناول أطروحات التيار القومي في تسع وعشرين صفحة، وناقش مواقف ممثلي التيار العلمي في ثمان وسبعين صفحة. وقد أصاب هذا الاختلال محتوى الأقسام ذاتا، حيث خُصَّ محمد عمارة مثثل التيار القومي الإسلامي بخمس وعشرين صفحة من العرض والتحليل والنقد العميق لطبيعة العمل الفكرائ (الإيديولوجي) الذي تناول به التراث وتعرجاته، وذلك من خلال كتبه: نظرة جديدة إلى التراث، والعرب والتحدي، وتيارات الفكر الإسلامي، واكتفى بأربع صفحات ونصف لعرض موقف الأرسوزي مثل التيار القومي العلماني، خصص ثلاثة أرباعها للاستشهاد بفقرات طويلة من مؤلفاته الكاملة دون تعليق أو نقد. والاختلال ذاته نجده في عرض آراء ممثلي التيار العلمي بشقيه: البراغماتي ويمثله زكي نجيب محمود (ص19)، والمعريف (الإبستمولوجي) ويمثله محمد عابد الجابري (ص56)، حيث قصر اختياره على كتاب زكي نجيب محمود تجديد الفكر العربي الصادر سنة 1973، ليحكم على "عودة الابن الضال" إلى رحاب "البيت الأبوي" بأها مراوغة، وقد كان الأجدر به الاعتماد على المططات الثلاث المترابطة التي لا يمثل هذا الكتاب إلا أولاها؛ أما المحطتان التاليتان فقد بتحلتا 
في كتابيه المعقول واللامعقول في تراثنا الفكري (1974)، وثقافتنا في مواجهة العصر (1976)، أو ربما كان حرياً به الاعتماد على كتاب قصة عقل (1983) لبناء موقف متكامل وأقرب إلى الموضوعية والجدة. ولا يمكن لهذه الاختلالات إلا أن تترك لدى القارئ تساؤلات منهجية عن مدى الجدوى في إقحام بعض الفصول في الكتاب، كذلك المخصص للتيار الماركسي، حيث رأى المؤلف أن نقده هو "للمنهج البتري" الذي كان يستعمله هذا التيار مع التراث ليس "من قبيل النقد فحسب بل أيضاً من قبيل النقد

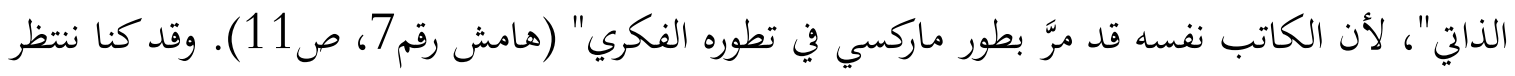
منه، وهو الماركسي القديم، وبحكم معرفته الدقيقة والواسعة (المفترضة) بأطروحات هذا التيار، أن يكون في تحليله أشمل وفي تقويمه أعمق للمناهج والأدوات التي استعملها ممثلوا هذا التيار في تشطير التراث وذبحه. وعلى الرغم من ادعائه التعرض لفرعي التيار الماركسي "القويم" و"غير القويم" (ص53)، (وانظر أيضاً ظهر الغلاف)، فإنه في الحقيقة لم يتعرض إلا لتوفيق سلوم مثثلاً للفرع "القويم"، ولم يتعرض لسمير أمين، الذي قال بشأنه: "قد يقال إن سمير ليس ماركسياً إلا بالهرطقة". وحتى في عرضه لأفكار سلوم لم نر منه غير جمل تبريرية من قبيل: "وبديهي أن هذه النزعة التشطيرية أو الانتقائية في الموقف من التراث كان لها ما يبررها" (ص12)، تحاول في مجمل سياقها تركَ انطباع عام أقل سلبية لدى القارئ يخفف الجرم عن القائمين به، وذلك على الرغم من رفضه لعملية الانتقاء المزيَّة للوعي كذلك.

ويتكرر ما قلناه آنفاً مع النموذج القومي العلماني في شخص زكي الأرسوزي الذي تعود أطروحاته إلى المرحلة السابقة لزيمة 1967، وهي من المفترض بذلك ألا قم المؤلف في هذا لكتاب (مثل كتبه "الجمهورية المثلى" الصادر 1956، أو "مشكلاتنا وموقف الأحزاب منها" الصادرة في 1958، أو "العبقرية العربية في لسانها"). وطرابيشي نفسه يقر بقدم بعض هذه النصوص (هامش17، ص20) وعدم خضوعها للتحديد الأولي للحظة الراهنة، فلماذا إذاً يكلف نفسه عناء حشرها هنا؟ وقد كان يكفيه أن يقصر عمله على نقد أعمال الجابري ومحمد عمارة وزكي نجيب محمود، دون تحديد إطار هيكلي قبلي يقوم له مقام الوعاء التاريخي والنظري الذي يجد نفسه مجبراً على ملئه. 
وإذا بتحاوزنا هذه المزالق المنهجية في كتاب جورج طرابيشي، فإن العمل النقدي والتتبع الذي قام به لأعمال الجابري وعمارة يستحق في ذاته الإشادة به والتوقف عند تعرجاته.

يأخذ المؤلف كتاب العرب والتحدي لمحمد عمارة مثالاً على الإشكالية موضوع الدرس ليسطر خيوط مذبحة "إرغام أربعة عشر قرناً من التاريخ العربي الإسلامي على الدخول في عنق زجاجة مخطط للتأويل الدلالي" (ص28). وتقوم هذه القراءة عند عمارة على قاعدة "أبستمولوجية" مؤسسة: ارتباط العقلانية بالقومية وارتباط الشعوبية بالظلامية أو اللاعقلانية. وعليه فإن كل ما هو غير عربي (والعروبة عنده حضارة وليست عرقاً) هو بالضرورة لاعقلاني ودون القومي. ولا يمكن لمثل هذه القراءة التأويلية أن تكون دون "ارتكاب خطيئتين بحق هذا التاريخ: الإسقاط والحذف" (ص33). وتبدأ العملية المنهجية الأولى في هذه المذبحة "بتأول العصر السالف على صورة واقع عصرنا ومثاله"، أي بما أن أجدادنا كانوا متقدمين عقلانياً وموحدين قومياً كان لا بد لنا من الأخذ بما أخذوا به هم، لا بد من استعادة ذلك "العصر الذهبي" والتمسك بتلابيبه، عوض الأخذ بما أتى به "الآخر" المتحدي للذات والمهيمن عليها، وبذلك يلتئم في الوقت نفسه "جرحنا النرجسي". وإذا استعصى إدخال مرحلة أو حالة من تاريخنا في "المخطط التأويلي الأيديولوجي" فإنه بكل بساطة يجري حذفها وبترها، أي يُكمم بعدمها، وتلك هي العملية المنهجية الثانية في ذبح تراثنا، كما يرى طرابيشي.

ويمضي جورج طرابيشي في مناقشة أفكار عمارة وأطروحاته، ولا يجد صعوبة كبيرة في كشف تحافت الكثير من تأويلاته وعدم صمودها أمام الحقيقة التاريخية، ويضرب عدة أمثلة عن "البززرة" التي يقوم .جا الكاتب لربطه ربط تطابق وتماثل كليين بين القومية العقلانية، إلى درجة تصبح معها عملية الحذف التاريخي القومية عند عمارة ولا عروبة ولا أمة بعد إنجاز دولة العرب الأولى إلى حدود القرن 3ه) مسيّة ومقرونة بحذف جغرافي أيضاً (توقف حدود الدولة العربية غرباً عند شرقي مصر وشرقاً عند شرقي العراق)، وهو بذلك الدولة العربية استبعاداً تحقيرياً عدائياً باعتبارهم يمثلون السبب الرئيس فيما نحن فيه من تجزؤ وتخلف. ولا يتردد محمد عمارة، كما يقرر طرابيشي، في "رفع "حقيقة" ارتباط العروبة بالعقلانية والعُجْمة باللاعقلانية إلى مرتبة القانون التاريخي" (ص43) ليصل في النهاية إلى نبذ كل ما أنتجته مرحلة ازدهار الحضارة العربية الإسلامية 
من تراث خلال القرون الأربعة اللاحقة لعصر المتوكل ومحنة المعتزلة والإلقاء به في سلة المهملات وخارج المخطط "القومي - العقلاني" (48)، ذلك أنه -أي عمارة- يقرن وصول العقلانية إلى أعلى ذراها بوصول التيار القومي إلى "قمة جهاز الدولة"، ويقصد بذلك ما قام به المعتزلة في عهد المأمون والمعتصم والواثق، كما يجعل بداية انحدار القَسمَة العقلانية للحضارة العربية الإسلامية مواكبة لانحلال قسمتها القومية. ولكن ذلك لا يمكن أن يستقيم تاريخياً، وهذا ما جعل طرابيشي يتوقف بالقارئ في العديد من المرات ليضرب له سيلاً من الشواهد المفندة لهذه الدعاوى. فإذا كان المعتزلة هم "طلائع المفكرين الذين بشروا بالاندماج الحضاري والانصهار القومي العربي" (تيارات الفكر الإسلامي)، فلا يفوتنا أن مؤسسيهم وأبرز قادقم كانوا من الموالي؛ وإذا كان الخلفاء العباسيون الثلاثة المأمون والمعتصم والواثق يمثلون ذروة الدولة القومية، فإن طرابيشي لا يفوته أن يذكر بأن أم الأول كانت فارسية، وأن ثالثهم من أم تركية وهو أول من اعتمد على عصبية عسكرية من المماليك الأتراك. بل إن أبرز "فقهاء العامة" الذين قادوا الانقلاب على المعتزلة، ممثلين لتيار "الفكر المحافظ المعادي للعقل"، - كما يرى طرابيشي- وفي مقدمتهم الإمام أحمد بن حنبل، كانوا من العناصر العربية وكان هواهم - فوق ذلك- قرشياً.

وليس غريباً، حسب قول محمد عمارة، أن يؤول وضع الحضارة العربية الإسلامية إلى التوقف، فالجمود، فالتراجع، في مسيرة انخطاطية لا رادّ لها تلاشت فيها القسَمَتان المميزتان لهويتها: القومية والعقلانية

ويصبح مضمون شعار إحياء التراث إذاً عند "السلفية العقلانية المستنيرة" التي يضع محمد عمارة نفسه تحت لوائها هو الرجوع إلى مرحلة ما قبل المتوكل، أي التاريخ السابق على منتصف القرن الثالث الهجري/التاسع الميلادي.

ولا يفوت جورج طرابيشي أن يورد في ناية عرضه قائمة طويلة من علماء هذا التراث العربي الإسلامي غير المعترف بمم في خخطط عمارة كالأشعري والبغدادي والشهرستاني وابن تيمية وابن جني والأصفهاني والثوحيدي وابن منظور وابن رشيق والجرجاني والفارابي وابن حزم وابن رشد والحلاج 
والغزالي وابن عربي والطبري والمسعودي وابن خلدون وابن بطوطة والرازي والحلي وغيرهم كثير، ويتساءل كيف يُطرد هؤلاء من دائرة التراث العربي الإسلامي ومن دائرة العقلانية والتقدم؟ بل وماذا يعني التراث العربي

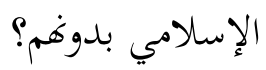

وإذا كان المسوغ للتيارين الماركسي والقومي في استعمال مباضعهم "الطبقية" و "العرقية" في التلاعب بمتن التراث العربي الإسلامي هو صدورهم عن هم أيديولوجي تتوقف حدود مصداقيته عند من يؤمن به، فإن المنهجيات العلمية تطمح - على العكس من ذلك- إلى "الحقيقة"، وتعتمد في الوصول إليها أكبر قدر من ضوابط الموضوعية والنسبية، وهنا يكمن خطرها لأها تسعى بذلك الادعاء إلى فرض نفسها على الجميع، فمن يستطيع ردَّ ثمار العلم "إلا غفل أو متحيز".

وعلى الرغم من أن طرابيشي يُنَوِه بجدية المحاولات العلمية التي شهدها حقل الدراسات التراثية في السنوات الأخيرة، ويهيي كل من يضع نفسه تحت لواء المنهجية العلمية، فإنه يحذر من خطورة انقلاب تلك المناهج نفسها إلى أيديولوحيات"علمية"، تعمل في التراث عمل البقية "بإخضاعه لتقنية الجراحة التشطيرية". ويتمثل هذه الخطر - في رأيه- في التضخم الواعي للهاجس الأيديولوجي أو في طغيانه اللاشعوري على منهج البحث. ويختار الكاتب ممثليْن لهذا التيار أولما، زكي نجيب محمود، رمزاً للمنهج العلمي البراغماتي. ومنذ البداية يعلن أنه سيكون "قاسياً بل هجائياً" معه، لأنه بقدر ما كان "يدعي" الانتماء إلى الوضعية المنطقية تارة وإلى الفلسفة التحليلية طوراً (وهما أكثر النزعات تعالياً على الأيديولوجيات حسب قول طرابيشي) يبدو في كتابه تجديد الفكر العربي - وهو الكتاب الذي يستشهد به المؤلف في طرح هذه الإشكالية- كاذباً في تمثيل مسرحية "عودة الابن الضال" (المذبحة، ص54). ولا بد من الإشارة هنا إلى أن اختيار طرابيثي لهذا الكتاب لم يكن مُوفقاً تمام التوفيق لأنه: أولاً قديم نسبياً قياساً على غيره من أعمال مؤلفه (إذ صدر سنة 1973)، ولأنه ثانياً يمثل المحطة الأولى لثلاثية كانت ثانيتها المعقول واللامعقول في تراثنا الفكري (1974)، وثالثنها ثقافتنا في مواجهة العصر (1976)؛ وقد جعلها مؤلفها تدور كلها في مدار واحد وتلتقي عند هدف رئيس هو "النظر في ثقافة عصرنا من جهة، ثم النظر في ثقافتنا الموروثة من 
جهة أخرى، بحثاً عن وسيلة تلتقي بها الثقافتان عند أبناء الأمة العربية في يومهم الجديد" (ثقافتنا في مواجهة

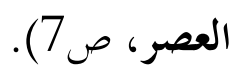

ونتساءل ألم يكن من الأجدى بالباحث، وهو يمكم على "عودة الابن الضال" بالكذب وعلى توجهه الجديد بالمراوغة، الاعتماد على كتاب قصة عقل الصادر سنة 1983م، الذي يسجل مسيرة أربعين سنة من التأليف (1980-1940)، رأى فيها زكي نجيب محمود نفسه "عقلاً صنع نفسه بنفسه، وهو راض كل الرضا عما صنع ويحمل تبعته أمام الله وأمام الناس" (قصة عقل، ص9)؟ وذلك مع الرجوع كلما اقتضى الحال إلى الثلاثية التي أشرنا إليها والتي تفصل ما أجمله الكاتب في قصة عقل وخاصة في بابئه الثامن: "رحلة في دنيا التراث"، والتاسع: "أصالة ومعاصرة".

إن "الصحوة القلقة" التي يتحدث عنها زكي نجيب محمود في كتابه تجديد الفكر العربي ليس صادقة عند طرابيشي، بل إن "التوبة" و"الندامة" اللتين يعلنهما لا يمكن أن تخفيا حقيقة المناورة و"التكتكة"، لأن الهدف من وراء ذلك لا يعدو أن يكون "إراحة الضمير" المعذب من سؤال ما فتئ يلح عليه ويؤرق ليله: "كيف يضمن أن يكون عربياً حقاً ومعاصراً حقاً"، أي "كيف السبيل إلى ثقافة موحدة.. يندمج فيها المنقول والأصيل في نظرة واحدة؟" (تجديد الفكر العربي، ص5). إن السبيل إلى ذلك كان الأخذ بالنفعية العملية والتطبيقية البحتة، أي "الانتقال من دروشة النصوص وشروحها وحواشيها إلى العلم ومخابيره ومعامله، ثم التصنيع بكل تقنياته" (المصدر السابق، ص239)، ويقى الهدف الوحيد للثقافة هو التقنية والتصنيع، ويصبح كل ما عداها "آثاراً محفوظة في المتاحف" (المصدر السابق، ص103)، كما تصبح "آدابنا وفنوننا ومعارفنا التقليدية كلها والتي كانت تحتكر عندنا اسم الثقافة... مادة للتسلية في ساعات الفراغ" (المصدر السابق، ص241). ويسطر زكي نجيب محمود الطريق الوحيد الممكنة للتحول والتقدم فيقول: "...لا... لم أعتد أشك لحظة في أن هذا هو الطريق، طريق التحول من تخلف إلى عصرية وهو أن نتتقل من "معرفة" قوامها الكلام إلى "معرفة" قوامها الآلة التي تصنع" (المصدر السابق، صريقي 239)، أي حسب رأي طرابيشي الارتماء كلياً في أحضان صانعي حضارة العصر وبالتحديد أوربا وأمريكا، والانقطاع تماماً عن ماضينا وتراثنا. ويصبح "قتل الميت" (التراث) الشرط الأول "لحياة الحي" (العصر)، أي استئصال هذا المعوق لتقدمنا، 
وبذلك يجيب عن السؤال الأول إجابة محددة وهائية، ويصبح مشروعه في إحياء التراث هو "في حقيقته العميقة مشروع لقتله" (المذبحة، ص65)، ويصبح المدف من قرار "عودة الابن الضال" إلى بيت أبيه هو القضاء عليه وعلى ما تبقى من ميراثه معاً (المذبحة، ص51).

لقد كان جورج طرابيشي بالفعل "قاسيا" في أحكامه التي خرج بها من تحليله ونقده للمنهج التشطيري الذي أسهم به زكي نجيب محمود في مذبحة التراث، مشككاً في دوافع هذه العودة إلى التراث ومقاصدها. وإذا كان له الحق في التساؤل وطرح الفرضيات والإشكاليات ووضع الإصبع على ما يراه داءً ينخر المنهج المستعمل في قراءة التراث وتوظيفه، إلا أنه يجانب الصواب في بنائه لأحكامه أو بعضها - مثلما رأينا قبل قليل- اعتماداً على جزء من الكل، ثم في تعميم موقفه ذاك من الجزء على الكل.

ويمكننا كذلك أن نقف عند "غلوائه" في حكمه القاطع النهائي على أن الطريق الذي اختاره محمود هو القطيعة التامة مع التراث والتوجه كلياً إلى حضارة الغرب، على الرغم من أن زكي نجيب محمود ما فتئ يردد عكس ذلك. ففي فصل "ثنائية السماء والأرض" من كتابه تجديد الفكر العربي مثلاً يقرر ما يلي: "لقد رك فشل الغرب نفسه، وهو واضع العلم الحديث، أن يقيم لنفسه مثل هذا اللقاء بين الطرفين، فكان العلم والكنه فقد الإنسان... وإنني لأعتقد أن مثل هذا الصراع بين الطرفين - بين مقتضيات العلم ومقومات الإنسان- والرغبة في إيجاد الحلقة التي توفق بينهما فتزيل الصراع هو ما تختلج به نفوسنا نحن، أبناء الأمة العربية اليوم"، لأن تلك الازدواجية المتآلفة في الثقافة العربية بين "فكر عقلي منطقي" و "وجدان صوفي وشعري" تبدو أمام عيني وكأفا قابلية فريدة وسمة بارزة يككن أن تكون أساساً متيناً لإقامة ثقافة عربية جديدة تصون أصالتها وتساير عصرها في آن واحد" (قصة عقل، صبيدي 177). بل إن محموداً يدعونا في مواقع عدة من ثلاثيته إلى أن نصنع صنيع آبائنا في المؤالفة بين العقل والوجدان في توازن دون ترجيح الجانب الحسي والنظرة العلمية الحسابية، أو جانب العاطفة والرغبة والانفعال أحدهما على الآخر. بل نجده أحياناً يتبرأ من جماعة "دمجت نفسها في حاضر الغرب كما هو، فخرجت هي الأخرى من ميدان المواجهة بالذوبان في عالم غير عالمها" (ثقافننا في مواجهة العصر، ص16). 
أما في الجزء الأخير من الملذجة، وهو أهم فصل فيه سواء من حيث حجمه (إذ يستغرق نصف الكتاب تقريبا) أو كثافة التحليل التي تميزه، فقد ناقش جورج طرابيشي ممثل التيار العلمي المعرئ (الأبستمولوجي) محمد عابد الجابري، محدداً إسهامه في "مذبحة التراث" هذه من خلال كتبه نحن والتراث،

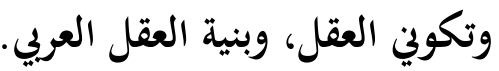

إن الجابري، وعلى عكس من سبقه، يدعونا إلى التنقيب في غور العقل الموروث والبحث في جذوره

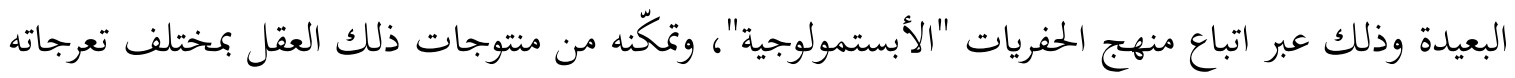

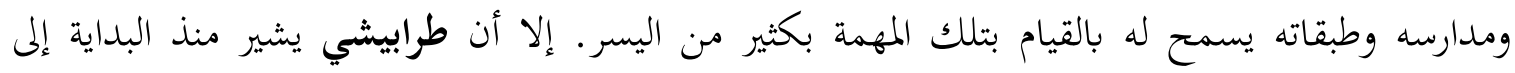

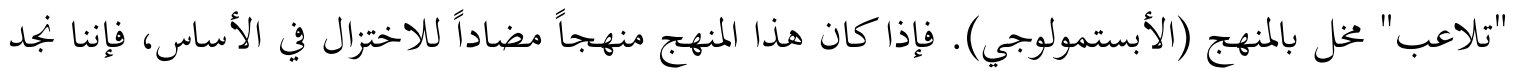
الجابري يستعمله ليرد العقل العربي إلى تعبيراته العقلية فقط، وتستحيل المعقولات موضوعه الوحيد، وكل الثعابير "الاعقلية" كالشعر والنثر الفني والنثر العلمي مطرودة - تبعاً لذلك- من دائرة العقل.

وهذا الاختزال قد أدى بححلل العقل العربي إلى "مأزق معرفي حقيقي" حسب قول جورج طرابيشي.

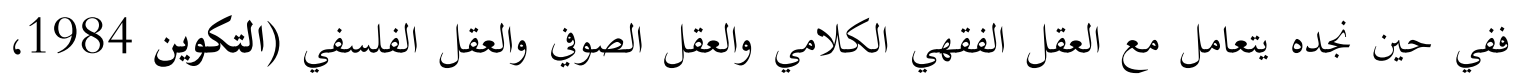
والبنية 1986) خاضعاً لإمرة أنظمة معرفية ثلاثة: البيان والعرفان والبرهان، نجده في العقل السياسي

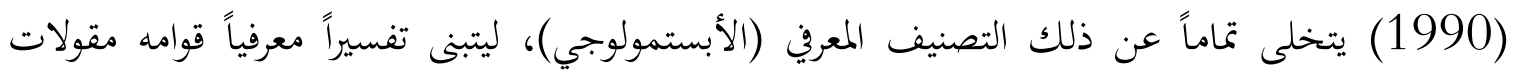
ثلاث: القبيلة والغنيمة والعقيدة. ويستنتج طرابيشي من ذلك غياب "تحليل أبتمولوجي قادر على الوصول

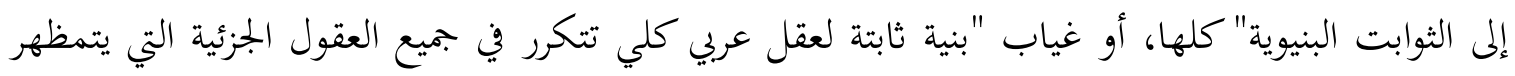

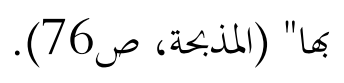

وإذا كان الجابري قد استبعد من حقل تحليله "الأبتمولوجي" قطاعات بكاملها من التراث العربي الإسلامي، إلا أن النزعة التشطيرية لا تسفر عن نفسها بجلاء وشطط، كما يرى جورج طرابيشي، إلا أن "العاهة" التكوينية التي يرزح منهجه "الأبستمولوجي" تحت وطأقا: تحول هذا المنهج في يديه إلى "أداة

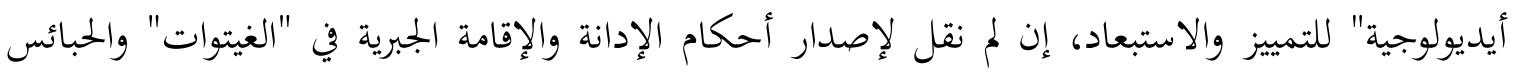

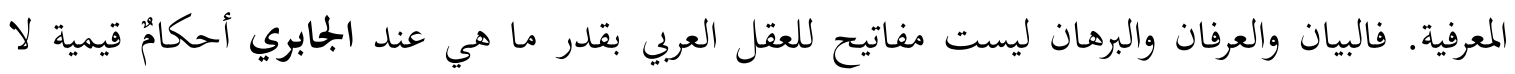


يجمع بينها سوى تضادها ذي الطبيعة المانوية: فالعرفان رجس رجيم، والبرهان خير عميم، أما البيان فهو فرس الرهان، فإن تحالف مع البرهان كتب له الفوزان الأصغر والأكبر، وإن تحالف مع شيطان العرفان قضي عليه بالهلاك الأبدي" (المذبحة، ص77).

هكذا إذن ومنذ البداية يصنف جورج طرابيشي مشروع الجابري، ويثور عليه لحشره عدة "أخلاط" و"أمشاج" ذات طابع هرمسي في خانة "اللامعقول العقلي" في قالب "المعقول الديني"، أو ما يطلق عليه تبخيساً واحتقاراً "العقل المستقيل"، وخاصة عندما تستحيل عنده هذه "الأخلاط" بالتدريج إلى "غابة الفكر الشيعي" مثثلة لشجرة الهرمسية. والربط بين دائرة اللامعقول والفكر الشيعي واحد من الثوابت التي يعتمد عليها الجحابري في تحليل هذا العقل، وإصراره على ذلك يحيلنا - حسب قول طرابيشي- إلى توحيد أشجار الفكر السني في غابة واحدة مقابلة تستظل وحدها بظلال "المعقول الديني"، بل أبعد من ذلك يذهب إلى

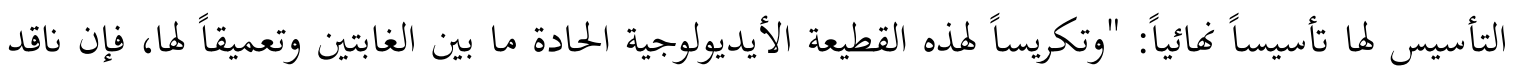
العقل العربي يعمِّدها - بغية إضافة المزيد من الشرعية "العملية" عليها- باسم القطيعة الأبستمولوجية، أي القطيعة التي تتعدى المضمون لتتأسس في المنهج ولتنحدر في النظام المعري بالذات" (المذبحة، صرئه). وعلى الرغم من أن الجابري يدفع عن نفسه قمة إثارة الحساسية الطائفية (البنية، ص285)، شعوراً منه بمبالغته في هذا الباب، فإنه يذهب أبعد من ذلك حسب قول طرابيشي، عندما يعتبر الشيعة، كل الشيعة، هم "الآخر"، ذلك الآخر الذي كانت تقاومه الدولة العباسية، "وبقي هو، لا يتغير في جميع مراحلها". وهنا يعترض عليه الباحث بشدة، ويعتبر الشيعة "ذاتاً" شريكة مثل السنة في بناء هذه الحضارة، كما يعتبر أن أيّ تأليب لشطر الذات على شطرها الآخر" حرب للذات على الذات" وإفقار لها (المذبحة،

ولكن، وعلى الرغم من مصداقية ثورة طرابيشي، وعلى الرغم من أن الجابري قد عمد في العديد من المواقع وبالتواء أحياناً إلى اختزال مثثلي "الرجعية" و "الظلامية" و"العقل المستقيل" في الشيعة بلا استثناء، أو في "الوعي القومي الفارسي" أو "الشوفينية الفارسية" باعتبارهم "موطن الهرمسية الآمن" (انظر الفصل التاسع من تكوين العقل العربي)، وعلى الرغم كذلك من اختصاره للصراع الدائر في الثقافة العربية الإسلامية عموماً 
بين نظامين معرفيين متباينين " يرتبطان بتيارين أيديولوجيين متصارعين تاريخياً: النظام البياني والأيديولوجية

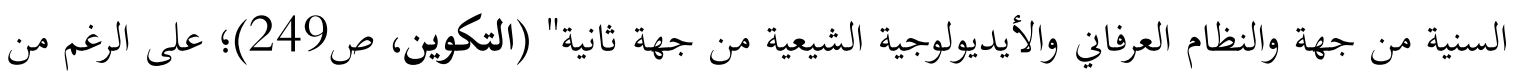
كل ذلك، فإن اعتباره الشيعة الباطنية "آخر" في الشاهد المذكور جاء في سياق تحليله التاريخي للنسق العام للخلافة العباسية، واختصار طرابيشي للشاهد (المذبحة، ص83) هو الذي أوحى بأن الشيعة يمثلون "الآخر العدو" الدائم للإسلام ماضياً وحاضراً، في حين أن الشاهد في مجمله يقول: "إن الدولة العباسية ككل قد عاشت زمناً سياسياً وأيديولوجياً واحداً بسبب أن "الآخر" الذي كانت تتحدد بالعلاقة معه تخركاتا السياسية قد بقي هو هو لا متغيراً خلال جميع التحولات التي عرفتها، وإن هذا الآخر هو الشيعة الباطنية" (التكوين، ص297، وكذلك ص296) (فقد أسقط الجملة المكتوبة بالحرف الغليظ من شاهد

وفي رأينا أن مناقشة الجابري كان يجب أن تكون قبل ذلك في ضوء مصداقية توحيده للزمن السياسي والأيديولوجي للدولة العباسية، ثم بعد ذلك هل صحيح أن الدولة العباسية - بإطلاق - قد اعتبرت المعارضة الشيعية "الآخر" النقيض الذي تتحدد هويتها بالقضاء عليه ونفيه خارج "الذات"؟ وهي التي غلبت وسادت في مراحل عدة من تاريخها بفضل مجهودات تلك المعارضة نفسها. ويمكن أن يُسَاءل أيضاً عن الانتقاء التوظيفي لمراحل وتيارات وشخصيات يستشهد بها ليدعم البناء الذي رسم هيكله مسبقاً ويتجاهل أو "يزّوِّر" ما يحرج دعاويه. وبعد أن يأسف جورج طرابيشي على ذلك التوظيف الأيديولوجي للمنهج "الأبستمولوجي" الذي قام به الجابري في سبيل "تعميق الانقسام وبتذير الاختلاف وتصعيد التنوع إلى تضاد ما هوي" (المذبحة، ص81)، يواصل مناقشة أطروحاته في ذبحه للتراث الفلسفي العربي الإسلامي مفنداً الأسس التي أقام عليها بناءه في هذا الفصل.

ففي حين ينظر الجابري إلى الحضارة العربية الإسلامية بوصفها واحدة من حضارات ثلاث "مارست ليس فقط التفكير بالعقل بل أيضاً التفكير في العقل: (التكوين، ص18)، فإن المصير الذي يرسمه لهذا العقل في النهاية هو في غاية "البؤس" (المذبحة، ص84) إذ باستثناء الكندي و "نصف" من الفارابي فإن تاريخ 
الفلسفة في الإسلام عنده - وإسلام المشرق تحديداً-يستحيل إلى تاريخ "استقالة العقل". ويتألق طرابيشي هنا في إبراز تمافت الجحابري سواء في حملته على جابر بن حيان "أول ناقل للعقل المستقيل الذي تحمله الهرمسية" إلى الثقافة العربية الإسلامية، أو في طرده لكبير أطباء المسلمين أبي بكر الرازي إلى حظيرة اللاعقلانية، أو في المجزرة التي يقيمها لإخوان الصفا جاعلاً منهم رواد الظلامية، ومن رسائلهم مدونة هرمسية كاملة، أو في تشنيعه "الهذائي" والمحموم على ابن سينا "أكبر مكرس للفكر الغيبي الظلامي في الإسلام"، أو في حملته المنظمة على التصوف الذي فتح - حسب دعواه- باب العقل البياني السني أمام الهرمسية. وقد اعتمد جورج طرابيشي أساساً لمناقشة ادعاءات الجابري وتتبع عمله المنهجي في النصوص التي اعتمدها، متوقفاً عند عمليات "التخريب" التي كان يقوم بها بما فيها من حذف وتشطير تأويل فاسد وقلب للحقائق... إلخ.

وهذه بعض الأمثلة التي توقف عندها طرابيشي وأطال فيها مناقشة الجابري ومراجعته"

- قام الجابري بخلط كبير (وهي عملية واعية ومخطط لها حسب رأبي) عند حديثه عن اسطفن الراهب أو اصطفن القديم بوصفه شخصاً واحداً أخذ عنه جابر بن حيان طريقته في التدبير الراجعة إلى هرمس مثلث الحكمة. وقد بين طرابيثي أفما شخصان مختلفان ذكرهما ابن النديم في فصلين مستقلين (على الرغم من ادعاء الجحابري الرجوع إليه في استقاء المعلومة)، وأن الذي أخذ عنه جابر هو شخص آخر واسمه، كما يذكر ابن النديم، الراهب فحسب. ولم يكف ذلك، بل إن الجابري سكت عمداً عن اشتغال جابر بصناعة المنطق وأنه أول من خصص له مؤلفاً، كما سكت عن كتابيه: كتاب الخواص الكبير، وكتاب الحدود، ليرى فيه فقط أول ناقل للهرمسية إلى الثقافة العربية الإسلامية.

- ويرتكب الجابري مع الرازي ما هو أفدح إذ يصر على جعله تلميذاً لجابر بمجرد أن ابن النديم يقول في الفهرست: إن الرازي كان يردد: "قال أستاذنا أبو موسى جابر بن حيان". ولا يشفع له اشتغاله بالطب

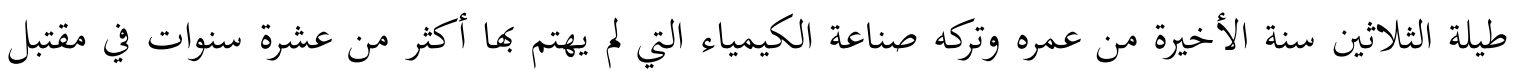
العمر ـ وعلى الرغم من أن أغلب من تكلم في الرازي أبعده تماماً عن الهرمسية وعن جابر، وعلى الرغم من إجماع مؤرخي الفلسفة العربية الإسلامية على اعتباره "عقلانيا خالصاً" (عبد الرحمن بدوي)، فإن محمد 
عابد الجحابري يصر على عده نموذجاً للفيلسوف اللاعقلاني" من خلال قراءة مبتسرة لمقدمة كتابه الطب الروحاني التي يمدح فيها العقل ويشيد بفضله. وقد عمد لتسويغ تخريجاته إلى حذف الجزء الأكبر من الشاهد الذي يتحدث فيه الرازي عن وظائف خمس للعقل (العق التكنولوجي ـ العقل المعري ـ العقل الميتافيزيقي العقل السيكولوجي - العقل المخض)، وقد قفز فوقها الجابري ليورد فقط الوظيفة السادسة وهي الوظيفة الأخلاقية، وبذلك يحكم على الرازي بأنه قتل العقل ولا يعترف إلا بالعقل "القامع للهوى". ويرى طاربيشي أن عملية التلاعب هذه منافية لأبسط قواعد العمل العلمي وأعرافه (المذبحة، ص92). وأكثر من ذلك يعمد الجابري إلى التلاعب بما تبقى من الشاهد فيسيء تأويله بتصويره لثنائية "العقل والهوى" على أها ثنائية هرمسية، لذلك فإن طرابيشي "ينصحه" في هذه الحالة بالزج بقطاع عريض وعميق من التراث العربي الإسلامي - وخاصة من تراث أهل السنة والجماعة- في جحيم "العقل المستقيل" لأغم يقولون بهذه الثنائية، بل ويؤسسون عليها خطاكم.

- يتهم جورج طرابيشي الجابري في الكثير من المواقع التي تكلم فيها على إخوان الصفا بأنه يبتر الشواهد بتراً، وأنه لم يقرأ قط رسائلهم بتمامها (ص100)، بل ربما لم يقرأ حتى النص الذي يستشهد به ولم يتصفح رسائلهم ولو مجرد تصفح (ص104).

فالجابري يأخذ على إخوان الصفا مهاجمتهم للمتكلمين لاستعمال قياس الغائب على الشاهد في حين يشيد بابن رشد لاستعماله هذه الحجة في التشنيع عليهم. فهل من المنطقي أن يؤدي اتخاذ الموقف نفسه إلى إخراج الأول من دائرة العقل وتنصيب الثاني على رأس تيار العقلانية؟

ويفند طرابيشي تماماً مقولة تشنيع إخوان الصفا على المتكلمين استعمالهم ذلك المبدأ مستشهداً بعدة من رسائلهم (الرسالة الثانية عشرة والرسالة الخامسة والأربعون التي بترها الجابري ولوى عنقها)، إنما الصحيح أفم يهاجموفم لإساءقم استعمال هذا القياس، ولعدم تمكنهم من إجرائه على أصوله (المذبحة، ص99)؛ إفم يأخذون على خصومهم وعلى خصوم الفلاسفة من المتكلمين جهلهم بأصول صناعة الجدل. 
وفي موضوع آخر يدعي الجابري أن إخوان الصفا يهاجمون الفلاسفة، ودليله على ذلك قولمم في إحدى رسائلهم"كل نبي بعثه الله فأول من كذبه مشايخ قومه المتعاطون الفلسفة والنظر والجدل".

ويورد طرابيشي الشاهد كاملاً ليؤكد أن موضوع الرسالة يدور على "العلوم الناموسية والشرعية" ولا يدور على الفلسفة، وهي الرسالة الخامسة والأربعون التي يقول مطلعها: "اعلم أن في الناموس أقواماً ستشبهون بأهل العلم ويتدلسون بأهل الدين، لا الفلسفة يعرفوغا ولا الشريعة يجققوها"؛ فالهجوم إذاً لا يعني الفلاسفة بل من لا معرفة لهم بالفلسفة. كما أن هذه الرسالة خصت "المشايخ" بالنقد فلأها رسالة في الدعوة وأصولها يحضون فيها أتباعهم على نشر دعوتم في صفوف الشباب دون الشيوخ. ويورد طرابيشي عدة أمثلة على مديح الفلسفة في رسائل إخوان الصفا (ص102-103) كقولم: "الفلسفة أشرف الصنائع البشرية بعد النبوة". ويقرر أن ما يمكن أن يؤخذ عليهم ليس هو تسفيه الفلسفة والتنكر لها، بل غلوهم في التَّوَمَة بينها وبين الشريعة كما تنبه إلى ذلك ناقدهم القديم السجستاني. - إنه لمن الظلم حسب رأي طرابيشي أن يقال عن إخوان الصفا: إفم تنصلوا من المنطق وناصبوه العداء، وهم الذين رفعوه أعلى المراتب، وخصصوا لغرضه ولشرح صناعته خمس رسائل كاملة من رسائلهم الاثنتين والخمسين (من الرسالة 10 إلى الرسالة 14). فقد قالوا في إحداها: "اعلم أن المنطق ميزان الفلسفة، وقد قيل: إنه أداة الفيلسوف، وذلك أنه لما كانت الفلسفة أشرف الصنائع البشرية بعد النبوة، صار من الواجب أن يكون ميزانُ الفلسفة: إنه التشبه بالإله بحسب الطاقة الإنسانية" (الرسائل، ج1، ص427). ويأخذ هذا الظلم لإخوان الصفا - برميهم في خانة المشنعين على العقل - "بعُعَ الفضيحة عند ما يقال لنا: إفم يربطون بين الحاجة للمنطق ودرن الأجساد، كما زعم الجابري. ويشهد ذلك "على أن ناقدهم لم يقرأ رسائلهم بتمامها وإلا ما كان تورط بإصدار مثل ذلك الحكم السلبي على موقفهم من علوم العقل (...) ويشهد على أكثر مما هو عدم قراءة: فنحن هنا أمام سوء قراءة يعز أن نقع على مثيله حتى في

$$
\text { أطروحات المبتدئين" (المذبحة، ص106). }
$$


وبعد أن ناقش طرابيشي موقف الجحابري من ابن سينا ومن المتصوفة بمختلف شعبهم وخاصة الغزالي الذي فتح بشكل غائي حصن السنة أمام الهرمسية كما ادعى الجابري، يصل إلى مناقشة هدفه العام من مشروع نقد العقل العربي وهو "الكف عن تقليد المشارقة" "وتأسيس ثقافة أصيلة مستقلة عن ثقافة أهل المشرق" (نحن والتراث، ص337-361). إن هدفه من القطيعة مع المشرق يأتي ضمن استراتيجية هضوية يقترحها علينا ويحدد معالمها على النحو الآتي: "إنه باستعادة العقلانية النقدية التي دشنت خطاباً جديداً في الأندلس والمغرب مع ابن حزم وابن رشد والشاطبي وابن خلدون، وبها وحدها، يمكن إعادة تأسيس بنية العقل العربي من داخل الثقافة التي ينتمي إليها، مما يسمح بتوفير الشروط الضرورية لتدشين عصر تدوين جديد في الثقافة العربية" (البنية، 566). والهدف من "المشروع الثقافي الأندلسي - المغربي" المبشر به هو الاستقلال التام عن كل ثقافة المشرق، لا بل ودعوة "المشرق" للانضواء تحت جناح هذا المشروع حتى يكسب فوائد العقلانية والنقدية، وينخرط في "بنية عقلية أخرى هي ذات البنية التي قام عليها الفكر الحديث في أوربا ولا زالت تؤسس التفكير العلمي إلى اليوم" (المصدر السابق، ص582).

وفي المتام، فإنا نعتقد أ الجحابري، وعلى خلاف ما يذهب إليه جورج طرابيشي، كان على اطلاع تام ودقيق بالنصوص التي استشهد بها أو أحال عليها في مشروعه. أما أعمال البتر والتشطير والتأويلات الفاسدة لبعض الشواهد من التراث العربي الإسلامي فقد جاءت لتحديده أهدافه وصورة البناء الذي يريد القيام به أولاً، ثم سعى إلى ملء ذلك الميكل وحشر كل ما يعترضه في القوالب المجهزة حتى وإن استعصت ظاهرياً عن 